\title{
Fracture resistance of abutment screws made of titanium, polyetheretherketone, and carbon fiber-reinforced polyetheretherketone
}

Eduardo Aloisio Fleck NEUMANN(a)

Cristina Cunha VILLAR ${ }^{(\mathbf{b})}$

Fabiana Mantovani Gomes FRANÇA(c) $^{\left({ }^{(2)}\right.}$

(a)Department of Implantology, Dental School, São Leopoldo Mandic - SLMANDIC, Campinas, SP, Brazil.

(b) San Antonio Dental School, Health Science Center, University of Texas, San Antonio, TX, USA.

(c)Department of Operative Dentistry, Dental School, São Leopoldo Mandic SLMANDIC, Campinas, SP, Brazil.

Declaration of Interests: The authors certify that they have no commercial or associative interest that represents a conflict of interest in connection with the manuscript.

Corresponding Author:

Fabiana Mantovani Gomes França

E-mail: biagomes@yahoo.com

DOI: 10.1590/1807-3107BOR-2014.vol28.0028 Epub XXXXX, 2014

Submitted: Oct 24, 2013

Accepted for publication: Mar 20, 2014

Last revision: Jul 07, 2014

\begin{abstract}
Fractured abutment screws may be replaced; however, sometimes, the screw cannot be removed and the entire implant must be surgically removed and replaced. The aim of this study was to compare the fracture resistance of abutment retention screws made of titanium, polyetheretherketone (PEEK) and 30\% carbon fiber-reinforced PEEK, using an external hexagonal implant/UCLA-type abutment interface assembly. UCLA-type abutments were fixed to implants using titanium screws (Group 1), polyetheretherketone (PEEK) screws (Group 2), and 30\% carbon fiber-reinforced PEEK screws (Group 3). The assemblies were placed on a stainless steel holding apparatus to allow for loading at $45^{\circ}$ off-axis, in a universal testing machine. A $200 \mathrm{~N}$ load (static load) was applied at the central point of the abutment extremity, at a crosshead speed of $5 \mathrm{~mm} /$ minute, until failure. Data was analyzed by ANOVA and Tukey's range test. The titanium screws had higher fracture resistance, compared with PEEK and 30\% carbon fiber-reinforced PEEK screws $(p<0.05)$. In contrast, no statistically significant difference was observed between the fracture resistance of the PEEK and the 30\% carbon fiber-reinforced PEEK screws $(p>0.05)$. Finally, visual analysis of the fractions revealed that $100 \%$ of them occurred at the neck of the abutment screw, suggesting that this is the weakest point of this unit. PEEK abutment screws have lower fracture resistance, in comparison with titanium abutment screws.
\end{abstract}

Keywords: Dental Implants; Titanium; Compressive Strength.

\section{Introduction}

Implant-supported restorations represent a predictable treatment option to replace single or multiple teeth, and present high success rates. ${ }^{1,2,3}$ The clinical success of implant-supported restorations depends largely on biomechanical factors related to the integrity of the bone/implant interface and the stability of the mechanical connection between implants and restorative components. ${ }^{4,5,6}$

Implant failure and complication rates are generally low., ${ }^{7,8}$ These unfavorable outcomes are usually associated with the presence of low-density bone, lack of primary stability, micro-motion during healing, peri-implant infection, abutment or prosthetic retaining screw loosening and fracture, and implant and/or framework frac- 
tures. ${ }^{6,9}$ The fracture of prosthetic components has different clinical consequences, depending on the component fractured and the location of the fracture. ${ }^{5,10,11}$ Along this line, the fracture of implant components may require treatment ranging from substitution of restorative components to surgical removal of osseointegrated implants. ${ }^{11,12}$

Abutment screw fractures are associated with inadequate screw tightening, screw loosening, improper occlusion concept, premature occlusal contacts, parafunctional habits, cervical misfit of the prosthesis and consequent fatigue of the screw material, fatigue character and yielding strength of

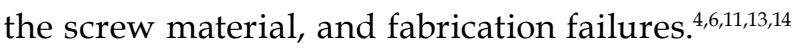
Fractured abutment screws may be replaced by new abutment screws. However, sometimes, the screw cannot be removed and the entire implant must be surgically removed and replaced. ${ }^{13,14}$

The physical properties and the design of screws and restorative components dictate their fracture strength and failure mode. ${ }^{7}$ Abutment screws can be made from a variety of materials. Nonetheless, these screws are typically made of titanium. Titanium is recognized for its high elastic modulus. The outcome of this property is that instead of absorbing masticatory forces, titanium transfers these forces to the adjacent bone, causing significant stress shielding. ${ }^{10}$ Polymeric materials have gained greater popularity in the field of orthopedic surgery, due to their high mechanical resilience and shock absorption properties. ${ }^{15}$ Therefore, abutment screws made from polymeric materials can be expected to limit the stress shielding between dental implants and the adjacent alveolar bone. Moreover, due to the low friction coefficient of polymeric materials, ${ }^{16}$ abutment screws made from these materials can be expected to have improved torque efficiency and be easier to remove in case of fracture.

Polyetheretherketone (PEEK) is a strong thermoplastic material produced from polyetheretherketone resin. Because of its high mechanical strength and durability, good electrical characteristics and outstanding resistance to hydrolysis, PEEK has been used extensively in aerospace, automotive, chemical, electronics, petroleum, and food and beverage industries. Recently, a medical-grade PEEK was developed
(PEEK-OPTIMA ${ }^{\mathrm{TM}}$, Invibio Biomaterial Solutions, Invibio Ltd., Lancashire, UK). Medical-grade PEEK has the same physical properties as PEEK; however, PEEK-OPTIMA $^{\mathrm{TM}}$ is also biocompatible, has high chemical resistance and resists several different sterilization methods. ${ }^{16}$

The main aim of this study was to compare the fracture resistance of abutment retention screws made of titanium, of polyetheretherketone (PEEK) and of $30 \%$ carbon fiber-reinforced PEEK, using an external hexagonal implant/UCLA-type abutment interface. The hypothesis of the study was that there was no difference between abutment screws made of titanium, PEEK and 30\% carbon fiber-reinforced PEEK.

\section{Methodology Sample Preparation}

Thirty (30) machined, self-tapping, regular platform, external hexagonal titanium screw implants $3.75 \mathrm{~mm}$ in diameter and $15 \mathrm{~mm}$ in length were used in this investigation (Titanium Fix ${ }^{\circledR}$, A.S. TechnologyTitanium Fix, São José dos Campos, Brazil, reference SPM315, batch \# 33409). These implants were inserted in auto-polymerized methacrylate acrylic resin (Dencôr Lay; Classico ${ }^{\circledR}$, São Paulo, Brazil [confirme, por favor]) contained in $12.7-\mathrm{mm}$ diameter, $25-\mathrm{mm}$ height, flexible PVC pipe cylinders (Tigre S/A, Joinvile, SC, Brazil). In brief, recipient beds were created, using the sequence of burs recommended by the implant manufacturer and a screw tap (A.S. Technology Titanium Fix, São José dos Campos, Brazil). Implants were then placed with a hand ratchet at $20 \mathrm{~N}$ (Titanium Fix ${ }^{\circledast}$, A.S. Technology - Titanium Fix, São José dos Campos, Brazil), until the implant neck reached the resin level. The abutments selected for this study were 30 anti-rotational straight titanium abutments (Titanium Fix ${ }^{\circledast}$, A.S. Technology - Titanium Fix, São José dos Campos, Brazil) recommended for cemented single crowns. Implant/abutment assemblies were randomly divided into three groups of ten each $(n=$ 10). Group 1: abutments were fixed to implants with titanium screws (2.5-mm diameter, 7.5-mm height, thread M 2.0, hexagonal fit); Group 2: abutments were fixed to implants with polyetheretherketone (PEEK) screws (Invibio Biomaterial Solutions, Invibio Ltd., Lancashire, United Kingdom); Group 3: abutments 
were fixed to implants with 30\% carbon fiber-reinforced PEEK screws (Invibio Biomaterial Solutions, Invibio Ltd., Lancashire, United Kingdom). Both the PEEK and the carbon fiber-reinforcement PEEK abutment screws were forged at a metallurgical factory specialized in micro-forging (Metalúrgica Menegotto Ltda., Cachoeirinha, Brazil) and were identical in size and shape to the titanium abutment screws. All the screws were tightened to $20 \mathrm{~N} \mathrm{~cm}$.

\section{Fracture Resistance}

The cylinders plus assemblies were tested by placing them on a stainless steel holding apparatus, inclined at $45^{\circ}$ to the vertical axis of the implant, enabling loading at $45^{\circ}$ off-axis, in a universal testing machine (EMIC DL 50, Equipamentos e Sistemas de Ensaio Ltda., São José dos Pinhais, Brazil). A $2000 \mathrm{~N}$ load (static load) was applied at the central point of the abutment extremity, at a crosshead speed of $0.5 \mathrm{~mm} / \mathrm{minute}$, until failure. $^{17}$ All fractures of the abutment screws were inspected visually and classified according to their location relative to the body of the screw, i.e., failure above screw head-neck, failure in the medium third, or failure in the inferior edge.

\section{Statistical Analysis}

The data was analyzed by ANOVA, and differences between the means were assessed by Tukey's range test. $P$-value for significance was set at $\leq 0.05$. Statistical analyses were performed using SAS (SAS Institute Inc., Cary, USA, Release 9.2, 2008).

\section{Results}

Titanium abutment screws had higher fracture resistance, in comparison with PEEK and with 30\% carbon fiber-reinforced PEEK abutment screws $(p<0.05)$, whereas no statistically significant difference was observed between the fracture resistance of the PEEK and the 30\% carbon fiber-reinforced PEEK abutment screws $(p>0.05)$ (Table 1$)$.

Finally, the visual analysis of the location of the fractions revealed that $100 \%$ of the fractions occurred at the neck of the abutment screw, suggesting that this is the weakest point of this unit.
Table 1. Fracture resistance of abutment screws (mean \pm standard deviation).

\begin{tabular}{lc}
\hline Abutment screws & Fracture resistance (N) \\
\hline PEEK & $149.5 \pm 33.8(\mathrm{~b})$ \\
Carbon fiber-reinforced PEEK & $145.2 \pm 43.8$ (b) \\
Titanium & $512.9 \pm 39.7$ (a) \\
\hline
\end{tabular}

Distinct letters indicate statistical differences between groups (Tukey, $p<0.05$ )

\section{Discussion}

It has been suggested that novel materials should be tested in making abutment screws, to ultimately achieve a higher preload, resistance to fracture, resilience to tension forces and lesser transmission of forces to the adjacent bone. ${ }^{17}$ This could prevent fractures of the abutment screw and the deleterious transmission of occlusal overloads to the marginal bone around dental implants, and subsequent bone loss. ${ }^{10}$

PEEK is a high performance semi-crystalline, non-homogeneous thermoplastic material that offers one of the highest strength-to-weight ratios available in a composite. It has high mechanical and physical properties and also a high degree of thermal and dimensional stability. Moreover, PEEK has strong abrasion resistance, is chemically resistant and is practically inflammable. It is noteworthy to mention that PEEK has an elasticity modulus similar to that of the bone..$^{15}$ Therefore, PEEK can be expected to absorb part of the forces generated during mastication and to limit their dissipation to the cervical area of the peri-implant bone. This characteristic, in turn, is likely to avoid peri-implant marginal bone loss caused by occlusal overload and eventual failure of implant-supported prostheses. ${ }^{12,18}$ In addition to these characteristics, the PEEK matrix allows the incorporation of carbon and glass fibers for the development of thermoplastic fiber composites. The addition of carbon fibers significantly increases the dimensional stability, toughness, hardness, flexural strength and resistance of PEEK. Interestingly, PEEK and PEEK composites are one of the few polymers used as metal replacements in several industries. ${ }^{16}$

Based on these properties of PEEK, this study aimed at comparing the fracture resistance of retention screws made of PEEK, 30\% carbon fiber-reinforced PEEK and titanium, using an external hexagonal 
implant/UCLA-type abutment interface. However, it was found that PEEK and 30\% carbon fiber-reinforced PEEK abutment screws have a lower fracture resistance compared with titanium abutment screws. This is consistent with findings of other investigators of polymeric materials, which showed that carbon reinforced PEEK demonstrated low resistance to compression. ${ }^{19}$ There are a couple of possible explanations for the results obtained in this study. First, it is likely that PEEK abutment screws may undergo extensive plastic deformation followed by fracture when subjected to compressive loading, due to their high flexural performance. ${ }^{6}$ Second, it is possible that the small dimensions or the manufacturing processing of PEEK and carbon fiber-reinforced PEEK abutment screws may have had a deleterious effect on the physical-mechanical properties of PEEK. With this in mind, it is plausible that carbon fibers were removed from the PEEK matrix during forging. It remains to be established if PEEK abutment screws

\section{References}

1. Adell R, Eriksson B, Lekholm U, Brånemark PI, Jemt T. Longterm follow-up study of osseointegrated implants in the treatment of totally edentulous jaws. Int J Oral Maxillofac Implants. 1990 Winter;5(4):347-59.

2. Jemt $\mathrm{T}$, Lekholm U. Implant treatment in edentulous maxillae: a 5-year follow-up report on patients with different degrees of jaw resorption. Int J Oral Maxillofac Implants. 1995 May-Jun;10(3):303-11.

3. Rocci A, Rocci M, Rocci C, Scoccia A, Gargari M, Martignoni M, Gottlow J, Sennerby L. Immediate loading of Brånemark system TiUnite and machined-surface implants in the posterior mandible, part II: a randomized open-ended 9-year follow-up clinical trial. Int J Oral Maxillofac Implants. 2013 May-Jun;28(3):891-5.

4. Cibirka RM, Nelson SK, Lang BR, Rueggeberg FA. Examination of the implant-abutment interface after fatigue testing. J Prosthet Dent. 2001 Mar;85(3):268-75.

5. Goodacre CJ, Bernal G, Rungcharassaeng K, Kan JY. Clinical complications with implants and implant prostheses. J Prosthet Dent. 2003 Aug;90(2):121-32.

6. Ribeiro CG, Maia MLC, Scherrer SS, Cardoso AC, Wiskott HWA. Resistance of three implant-abutment interfaces to fatigue testing. J Appl Oral Sci. 2011 Aug;19(4):413-20.

7. Strub JR, Gerds T. Fracture strenght and failure mode of five different single-tooth implant-abutment combinations. Int J Prosthodont. 2003 Mar-Apr;16(2):167-71. of other designs and sizes or processed by different manufacturing technologies have better mechanical properties. Another study, comparing the fracture resistance of screws made both of commercially pure titanium and of a titanium-gold alloy, also demonstrated that commercially pure titanium screws have higher fracture resistance, and fracture at about $500 \mathrm{~N}$ under oblique forces. ${ }^{17}$

This study showed, for the first time, that PEEK abutment retention screws have lower fracture resistance, compared with titanium abutment screws. Nevertheless, further studies are required to elucidate the mechanical and fatigue properties of PEEK screws in internal implant/abutment interfaces under cyclic loading.

\section{Conclusion}

In conclusion, PEEK abutment screws had lower fracture resistance, compared with titanium abutment screws.

8. Tripodakis AP, Strub JR, Kappert HF, Witkowski S. Strength and mode of failure of single implant all-ceramic abutment restorations under static load. Int J Prosthodont. 1995 May-Jun;8(3):265-274

9. Kronstrom M, Svenson B, Hellman M, Persson GR. Early implant failures in patients treated with Branemark system titanium dental implants: a retrospective study. Int J Oral Maxillofac Implants. 2001 Mar-Apr;16(2):201-7.

10. Balshi TJ. An analysis and management of fractured implants: a clinical report. Int J Oral Maxillofac Implants. 1996 Sep-Oct;11(5):660-6.

11. Patil PG. A technique for repairing a loosening abutment screw for a cement-retained implant prosthesis. J Prosthodont. 2011 Dec;20(8):652-5

12. Adell R, Lekholm U, Rockler B, Brånemark PI. A 15-year study of osseointegrated implants in the treatment of edentulous jaw. Int J Oral Surg. 1981 Dec;10(6):387-416.

13. Nergiz I, Schmage P, Shahin R. Removal of a fractured implant abutment screw: a clinical report. J Prosthet Dent. 2004 Jun;91(6):513-7.

14. Santos MDB, Pfeifer AB, Silva MRP, Sendyk CL, Sendyk WR. Fracture of abutment screw supporting a cemented implant-retained prosthesis with external hexagon connection: a case report with SEM evaluation. J Appl Oral Sci. 2007 Apr;15(2):148-51. 
15. Steinberg EL, Rath E, Shlaifer A, Chechik O, Maman E, Salai M. Carbon fiber reinforced PEEK Optima - A composite material biomechanical properties and wear/debris characteristics of CF-PEEK composites for orthopedic trauma implants [Internet]. J Mech Behav Biomed Mater [cited 201407 4]. 2013 Jun;17:221-8. Available from: http://www.sciencedirect.com/science/article/ pii/S1751616112002573. DOI: 10.1016/j.jmbbm.2012.09.013.

16. Invibio Biomaterial Solutions. PEEK-OPTIMA POLYMER. Product manual [homepage on the Internet]. 2004 [cited 2012 Feb 15]. Available from: http://www.invibio.com.
17. Erneklint $C$, Ödman P, Örtengren U, Karlsson S. An in vitro load evaluation of a conical implant system with 2 abutment designs and 3 different retaining-screw alloys. Int J Oral Maxillofac Implants. 2006 Sep-Oct;21(5):733-7.

18. Asvanund P, Morgano SM. Photoelalastic stress analysis of external versus internal implant-abutment connections. J Prosthet Dent. 2011 Oct;106(4):266-71.

19. Yurgartis SW, Sternstein SS. A micrographic study of bending failure in five thermoplastic-carbon fiber composite laminates. J Mater Sci. 1988 May;23(5):1861-70. 